\title{
Parental Differential Treatment in Families with a Child with a Developmental Disability
}

\author{
Marie-Michèle Truchon and Nina Howe \\ Concordia University
}

\begin{abstract}
Using distributive justice theory as a framework, the purpose of the present mixed methods study was to determine whether parental differential treatment was present and if so, to what degree, in families of children with a developmental disability. Moreover, if present, we examined to what extent parental differential treatment impacted family dynamics. One bilingual (i.e., French-English) family and eight Frenchspeaking families, which were all middle-class families, participated. Mothers, fathers, and siblings who are typically developing were individually questioned during semi-structured interviews and completed the Sibling Inventory of Differential Experiences-Revised questionnaire. Children also completed the Perceived Fairness of Parental Differential Treatment measure. All quantitative data generated by the questionnaires were analyzed descriptively using the SPSS program, whereas interviews were coded using qualitative methods. Specifically, in vivo and axialthematic coding of the interview data revealed that, according to both parents and children, the degree of parental differential treatment varied across families of children with developmental disabilities; yet, differential treatment was often justified and perceived as necessary by parents and children. These findings provided an overview of struggles and blissful moments that families of children with developmental disabilities may encounter on a daily basis. Implications for practitioners and policy are discussed.
\end{abstract}

Families in which there is a child with a developmental disability (DD) present unique challenges for family life (Hodgetts, Zwaigenbaum, \& Nicholas, 2015). Disabilities can include a range of diagnoses, for example autism spectrum disorder (ASD), pervasive 
developmental disorder, Rhett syndrome, and various intellectual and language impairments. The Canadian Survey on Disability, 2012 identified that $13.7 \%$ of Canadians over 15 years of age have a disability (Bizier, Fawcett, Gilbert, \& Marshall, 2012). As one example of a DD, recent evidence indicates that approximately 1 in 66 Canadian children and youth between the ages of 5 and 17 are diagnosed with ASD (Statistics Canada, 2018). Clearly, a significant number of Canadian families have a child with a DD, which can impact the family as a whole (e.g., Weiss, Wingsiong, \& Lunsky, 2014). While discussing family-systems perspectives, Schuntermann (2007) argued that having a child with a DD may influence family dynamics in different ways, for example how parents divide their caregiving and attention among all the children in the family. Clearly, children with a DD have unique needs that require individualized attention from caregivers (Hoefman et al., 2014). Consequentially, caregivers are often conflicted as to how to best care for all their children, while providing similar and fair amounts of attention (Jensen, Whiteman, Fingerman, \& Birditt, 2013). This issue is termed parental differential treatment and includes two components: control (e.g., directives, behaviour management) and affection (e.g., warmth, hugs; Daniels \& Plomin, 1985).

Studies have examined the impact of parental differential treatment on relationships between siblings who are typically developing (TD) and children with a DD (e.g., Kowal \& Kramer, 1997). Children's physical and social environments play a major role in their development; thus parental differential treatment can sometimes be detrimental, for example by evoking disagreements and competition among siblings, although under some circumstances, children perceive parental differential treatment as fair (Kowal \& Kramer, 1997). Nevertheless, few qualitative studies have considered fathers' perspectives and both parents' viewpoints on differential treatment. Employing distributive justice theory as a guide for the present study, we employed a mixed method approach but primarily adopted a qualitative approach to provide a rich analysis of family members' perspectives on parental differential treatment when one child has a DD. Interviews with parents and siblings and questionnaires were analyzed to develop an understanding of family dynamics, specifically, the perspectives of parents and siblings who are TD on parental differential treatment and whether it is perceived as fair or unfair.

\section{Distributive Justice and Parental Differential Treatment}

Understanding family dynamics can be particularly challenging; however, Deutsch (1985) articulated the distributive justice framework, which stipulated that most individuals hold strong beliefs about whether family resources are dispensed proportionally (DetteHagenmeyer \& Reichle, 2016; Meunier et al., 2012; Sabbagh \& Schmitt, 2016). Children may have diverse reactions when sensing unequal treatment, for example becoming withdrawn, angry, or aggressive. In fact, Meunier et al. (2012) reported children are likely to experience negative emotions when there is a disconnect between actual treatment and how they feel they should be treated. Further, these authors highlighted that children's perceptions of parental differential treatment was related to the extent to which it affected the children and the family as a whole. Children may feel anxious, upset, and saddened when parents spend a greater amount of time with their sibling(s) (Kowal, Kramer, Krull, \& Crick, 2002; Meunier et al., 2012). However, negative emotions may not be as apparent when children perceive differential treatment as necessary (Kowal \& Kramer, 1997; 
Meunier et al., 2012), thus emphasizing the importance of inquiring about the perceived fairness of differential treatment. In fact, children are likely to demonstrate compassion and understanding when recognizing that their sibling requires more time given a specific need or DD as discussed next (Kowal \& Kramer, 1997).

\section{Parental Differential Treatment in Families of Children with a DD}

Families of children with a DD are often confronted with an overwhelming number of competing demands (Schuntermann, 2007). Accounting for the basic needs of children who are TD is often challenging for parents, but becomes increasingly demanding when a child is diagnosed with a DD. In accordance with family systems perspectives, family dynamics may be altered dramatically when a child is diagnosed with a DD (Schuntermann, 2007). Families with such a child often have limited access to resources, thus leaving them isolated and uncertain about appropriate ways to care for their whole family (Engle \& Black, 2008; Hodgetts et al., 2015; Mereoiu, Bland, Dobbins, \& Niemeyer, 2015).

Traditionally, parental differential treatment was assessed in families with children who are TD (e.g., Kowal \& Kramer, 1997), although a few studies have also investigated families with a child with a DD or medical diagnosis (McHale \& Pawletko, 1992; Quittner \& Opipari, 1994). For example, McHale and Pawletko (1992) examined parental differential treatment and its impact on sibling relationships and children's adjustment in children aged 8-14 years and their mothers; approximately half of the families had a child with a disability. Parental differential treatment was reported to occur more often in families with a child with a DD compared to families in which all children are TD. Although differential treatment was deemed necessary by most siblings, some individuals still reported feeling anxious and/or excluded. Thus, McHale and Pawletko (1992) suggested examining the context in which parental differential treatment occurs before reporting its potential consequences for children's development and the quality of their relationships.

Parental differential treatment of siblings was also assessed by Quittner and Opipari (1994) in a study of mothers caring for toddlers and preschoolers where some children had a history of cystic fibrosis while others had no medical needs. Data were collected using home and phone interviews and rating scales, as well as daily diaries. Interestingly, during the interviews, children reported few or no instances of parental differential treatment. On the other hand, the diary data revealed differences in how children were treated in families with and without a child with cystic fibrosis. Specifically, higher levels of parental differential treatment were reported in families of children with cystic fibrosis, which was considered necessary given the developmental needs of the children. In contrast, low levels of differential treatment were found in families of children with no diagnoses. Overall, these results highlighted the importance of providing details about the family environment in which parental differential treatment is reported.

Wolf, Fisman, Ellison, and Freeman (1998) evaluated the effects of parental differential treatment in families that included a child with either a pervasive developmental disorder, Down syndrome, or no developmental disorder (i.e., control group). In a 3-year longitudinal study, the authors investigated the behavioural adjustment of children who are TD. The participants completed a variety of questionnaires (e.g., Social Support Scale for Children, Survey Diagnostic Instrument). 
Although the experiences of children with and without a sibling with a DD differed significantly, the results indicated that adjustment difficulties surfaced with the children whose sibling had a pervasive developmental disorder or Down syndrome. It should be noted that adjustment difficulties (i.e., internal and external problem behaviours) were mainly evident when siblings of children with a pervasive developmental disorder were treated favourably; these results emerged in both assessments. In contrast, as identified in the second assessment, children with a sibling with Down syndrome experienced internalizing adjustment difficulties when their sibling was the recipient of preferred treatment. Lastly, care and support from the community (e.g., teachers) had a beneficial impact on all brothers and sisters. Overall, this study demonstrated how different diagnoses may differentially impact siblings' behaviour.

Kowal and Kramer (1997) employed an attribution and social information theoretical framework to examine children's views about parental differential treatment in families in which all the children (aged 11-13) were TD. The results indicated that $75 \%$ of the interviewees did not report any instances of parental differential treatment, whereas when children reported instances of this parental behaviour, they stated that the differential treatment was justified given their sibling's current repertoire of skills and needs. Overall, children who perceived parental differential treatment as necessary appeared to be more satisfied with their sibling relationship(s), suggesting that the acceptance of this parental behaviour was not necessarily detrimental to quality of the sibling relationship.

Together these findings provide important insights into the journey of families with a child with a DD. Most studies principally focus on obtaining quantitative data regarding the views and behaviours of children and mothers regarding parental differential treatment (Dyson, 1989; McHale \& Pawletko, 1992; Wolf et al., 1998). Only a handful of studies highlight the importance of incorporating both mothers' and fathers' perceptions and beliefs when investigating the phenomenon (e.g., Brody, Stoneman, \& McCoy, 1992; Goldberg, Marcovitch, McGregor, \& Lojkasek, 1986; Kowal \& Kramer, 1997; McHale, Crouter, McGuire, \& Updegraff, 1995; Quittner \& Opipari, 1994; Volling \& Belsky, 1992). To the best of our knowledge, there is a paucity of qualitative phenomenological studies examining fathers' perceptions of parental differential treatment in families with a child with a DD. Capturing the perspectives and experiences of both parents will enrich our understanding of the dynamics of families in which there is a child with a DD. Additionally, a qualitative approach allows for a richer examination of family dynamics, affording a fuller comprehension of the daily struggles of these families.

\section{The Present Study}

The present mixed method (i.e., qualitative phenomenological and quantitative) study employed distributive justice theory as a conceptual framework to address whether parental differential treatment was present in families with a child with a DD. Specifically, we investigated whether parental differential treatment was recognized by the children who are TD and by both mothers and fathers, and if so, whether it was perceived as fair or unfair. Fathers were included in this study as a means of addressing the limitations in the literature and enhancing our understanding of family dynamics in families with a child with a DD. To do so, nine families including both parents and the 
children who are TD answered questionnaires and were interviewed regarding their perceptions of parental differential treatment and its impact on family life.

\section{Method}

\section{Participants}

Nine French- and English-speaking middle-class, Caucasian families were recruited from a large, urban community in Canada; except for one single-mother family, all included a mother, father, and children. Only one family was bilingual (i.e., FrenchEnglish) and the other eight were unilingual French-speaking. The number of children in families varied; seven families had two children, one family had three, and one had five. Four males and six females who were TD were included in this study; the gender of the children with a DD included six males and three females. Six participants were younger than their sibling with a DD, one was older, and three were the same age (one was a twin and two were from a set of triplets). The mean age of children who participated in this study was 9 years $(S D=1.63$ years $)$. Eligibility criteria required families to have children aged between 4 and 14 years with at least one child with a DD.

Most parents utilized the term $A S D$ to describe their children's DD; other terms mentioned by parents included neurodevelopmental, mental, and/or behavioural conditions, such as attention deficit disorder and Guinon's disease. Some parents disclosed diagnosis specifiers, such as intellectual impairment and/or language impairment. Other diagnoses reported by parents included Rett syndrome and epilepsy. It should be noted that all diagnoses were based on parental reports. Parents also rated the level of functioning of their child with a DD; five rated their child as requiring very substantial support; two, as requiring substantial support; and two, as requiring support.

\section{Procedure}

Families were recruited using flyers, word-of-mouth, local organizations, and online platforms (e.g., Facebook) and they volunteered to participate. Informed parental consent and the assent of the child(ren) who are TD were obtained prior to beginning the study; the child with the DD was not interviewed. One of us (first author) established rapport at the beginning of each session while talking with each family member. After receiving brief instructions, families were given the opportunity to choose which component (i.e., questionnaires or interview) they wished to participate in first. Parents were invited to complete the questionnaires individually and privately, while the instructions were read aloud to the sibling(s) who are TD, who were given assistance if required. Interviews were conducted at the participants' respective residences in a room of their choice and were conducted separately for mothers and fathers. Interviews were transcribed (in French), carefully reviewed, and analyzed by the first author and a research assistant who was naive to the study's goals. It should be noted that in this article, most of the quotations from participants were translated from French to English. Lastly, participants were sent a summary by email explaining the results of the study. The study received ethical approval from Concordia University's Office of Research prior to beginning recruitment. 


\section{Measures}

Demographic questionnaire. Parents completed a demographic questionnaire (i.e., age, gender, marital status, employment, education, annual income, cultural and religious affiliation). Information regarding their children (e.g., gender, date of birth, birth order) was also requested.

Sibling Inventory of Differential Experiences-Revised (SIDE-R). The SIDE-R was originally developed by Daniels and Plomin (1985) and comprises four sub-scales: differential sibling interaction, differential parental treatment, differential peer characteristics, and events specific to the individual. However, only the differential parental treatment sub-scale was administered in the present study. Two different forms were used: a parent and a child version. Both forms specifically assessed affection and control. Sample questions from the parent's version include: "Have been strict with him/her" (i.e., differential control) and "Have shown interest in the things he/she likes to do" (i.e., differential affection). Similarly, the child version is comprised of questions, such as: "Our mother/father tended to favour one of us" (i.e., differential affection) and "Our mother/father punished us for our misbehaviour" (i.e., differential control). Items were rated from 1 (much more with me/child who is TD) to 3 (about the same) to 5 (much more with my sibling/child with a DD) for siblings and parents. Mothers, fathers, and the children who are TD all completed the questionnaire independently.

Perceived fairness of parental differential treatment. Devised by Kowal and Kramer (1997), the Perceived Fairness of Parental Differential Treatment scale is used to determine if items on the SIDE-R are rated as fair or unfair by the children who are TD. Each item was either read independently by the participants or read aloud to the child by the first author. They then rated each item as fair (scored as 1) or unfair (scored as 2). Participants responded to this question by pointing to or circling their answers on the questionnaire.

Interviews. Semi-structured interviews were used to gather information on mothers, fathers, and siblings' experiences with respect to parental differential treatment (Hays \& Singh, 2012). The same set of questions on time and attention, demands and tasks, and family dynamics were used with both parents, who were interviewed separately; children were also interviewed independently. For instance, parents were asked: "Do you feel like you spend more time with one child than the other?" Additional interview questions on activities, responsibilities, and rules were developed for the siblings: "What kind of rules are in your house?" Probing questions were also used to clarify information and obtain more details about the participants' experiences. Interviews conducted with parents lasted approximately 15-20 minutes, whereas interviews with the siblings lasted 5-10 minutes. More specifically, the average length of the childrens' interviews was 9 min $29 \mathrm{~s}$ (range = $5 \min 14 \mathrm{~s}$ to $16 \min 23 \mathrm{~s}$ ) and $15 \mathrm{~min} 11 \mathrm{~s}$ (range $=4 \min 14 \mathrm{~s}$ to $30 \mathrm{~min} 19 \mathrm{~s}$ ) for the parents' interviews.

Role of the interviewer. The first author created the research questions based on the relevant literature reviewed earlier and also on knowledge developed through working with children with a DD. Further, it should be noted that she had an outgroup status, meaning that she does not have a sibling or an immediate family member with a DD. 


\section{Data Analysis for the Interviews}

A set of codes was initially developed using the participants' words, known as in vivo coding (Saldaña, 2013). This method was employed to ensure that their experiences were accurately portrayed. In the next step, focused coding was used first, followed by axial-thematic coding. The codes previously developed were then gathered into a concept map, from which broader concepts were formed. The same procedures were followed for the siblings', mothers', and fathers' transcripts.

\section{Results}

\section{Children's and Parents' Perceptions of Parental Differential Treatment and Fairness}

The descriptive statistics obtained from the two sub-scales (affection and control) of the SIDE-R as completed by children, mothers, and fathers are found in Table 1. Overall, both children's and parents' mean ratings were close to the mid-range score of three on the SIDE-R, indicating that they generally treated both children (TD and with a DD) in similar ways. Children rated mothers as somewhat higher in differential control and affection than fathers in the direction of the sibling with a DD. On the other hand, mothers and fathers rated themselves as highly similar on differential control in the direction of the sibling with a DD; mothers viewed themselves as slightly higher on differential affection with the child with a DD than fathers. Fathers rated themselves as providing the same level of affection to all children in the family. Table 2 presents findings on the Perceived Fairness of Parental Differential Treatment scale; both affection and control by mothers and fathers was generally perceived as fair by the children. These findings should be taken cautiously given the small sample size. The qualitative analyses delved into these issues more deeply but generally confirmed the results of the questionnaire data.

Table 1

Ranges, Means, and Standard Deviations for the Sibling Inventory of Differential Experiences-Revised Questionnaire

\begin{tabular}{lcccc}
\hline \multicolumn{1}{c}{ Items } & $\boldsymbol{n}$ & Range & $\boldsymbol{M}$ & $\boldsymbol{S D}$ \\
\hline Differential control reported by mothers & 9 & $3.00-4.75$ & 3.72 & 0.64 \\
Differential control reported by fathers & 8 & $2.50-5.00$ & 3.75 & 0.86 \\
Differential affection reported by mothers & 9 & $2.80-4.60$ & 3.27 & 0.54 \\
Differential affection reported by fathers & 8 & $2.60-3.40$ & 3.00 & 0.30 \\
Differential control (mothers) reported by the child & 9 & $2.50-5.00$ & 3.49 & 0.75 \\
Differential control (fathers) reported by the child & 9 & $2.75-5.00$ & 2.64 & 0.72 \\
Differential affection (mothers) reported by the child & 9 & $2.80-3.80$ & 3.09 & 0.30 \\
Differential affection (fathers) reported by the child & 9 & $2.40-3.20$ & 2.84 & 0.24 \\
\hline
\end{tabular}

Note. Each item could be rated on a scale from $1=$ much more with me/child $A$ to $3=$ about the same to $5=$ much more with my sibling/child $B$ for siblings and parents, respectively 
Table 2

Ranges, Means, Standard Deviations, and Variance for the Sibling Inventory of Differential Experiences Questionnaire-Fairness Evaluation by Children

\begin{tabular}{lccccc}
\hline \multicolumn{1}{c}{ Sub-scales } & Questions $(\boldsymbol{N})$ & Fair $(\boldsymbol{n})$ & Unfair $(\boldsymbol{n})$ & $\boldsymbol{M}$ & $(\boldsymbol{S D})$ \\
\hline $\begin{array}{l}\text { Differential control } \\
\text { Mothers }\end{array}$ & 36 & 28 & 8 & 1.22 & $(0.26)$ \\
Fathers & 36 & 27 & 9 & 1.26 & $(0.44)$ \\
$\begin{array}{l}\text { Differential affection } \\
\text { Mothers }\end{array}$ & 45 & 43 & 2 & 1.03 & $(0.10)$ \\
Fathers & 45 & 44 & 1 & 1.01 & $(0.03)$ \\
\hline
\end{tabular}

Note. The rating scale for each item ranged from $1=$ fair to $2=$ unfair.

\section{Children's Interviews}

Three themes emerged from the children's interviews regarding parental differential treatment and experiences in the family.

Activities dedicated exclusively to children who are TD. Children were forthcoming about their feelings in response to: "What kind of 'special time' or 'special activities' do you have with your parents?" Child 1 (younger than child with a DD) stated: "Sometimes I cuddle with mom." After being verbally prompted, he further mentioned: "We play hockey because later we will go skating, so we played hockey a little bit." Child 8 (same age as child with a DD) discussed activities that she engages in with both of her parents:

When it is with my mother, it's like, when my sister is at her friend's house, my father is in the basement working, and my brother is doing his own thing in the basement, and sometimes I go shopping with my mother, and yes, that's fun. With my father it's like he cooks duck, okay, and we go get the ducks at [location], so we do kind of a road trip. It's like one hour and a half, and it's fun.

Similarly, Child 3 (younger than child with a DD) discussed the types of activities she completes with her parents when her brother with a DD goes to respite camps:

Well, when my brother goes to respite camps, well, we have time just the three of us together, but it's quite rare; but we spend time together when he is in his bedroom, and we watch movies together.

In response to the question about shared time and activities with parents, Child 6 (younger than child with a DD) said, "It's, really rare." She further mentioned: "Sometimes me, well very, very rarely my mother and I go shopping while my grandmother babysits my brother." This view was echoed by Child 4 (older than child with a DD) who said, "I don't really do activities with both of my parents." In addition, Child 2 (same age as child with a DD) stated, "Sometimes I go with, with mommy to the movies." Lastly, one child shared that he did not have any "special" time or activities with his parents: "No, we have had special activities in the past, but the entire family was there." 
Family rules for children who are TD and siblings with a DD. The majority of children recognized that family rules were an issue. Child 3 (younger than child with a DD) initially expressed that rules differed in magnitude for each child in the family:

We can't yell at everyone. And it depends for the people because sometimes we get frustrated, and we yell at each other. But my brother is mad and one, a second later he is really happy, and he always wants to do everything, so it's not the same rules between him and me.

When asked about whether she found the strategies used by her parents to be fair, she stated:

No, not necessarily because him, me, I go in my bedroom for one hour, and he only goes for five minutes, and after he gets out, he says sorry. I have to wait one hour before I can say sorry, and it's a similar situation.

The experience of Child 6 (younger than child with a DD) was similar to that of Child 3, who mentioned: "I'm not allowed upsetting him." She further stated: "My brother has no rules at all. It's a little unfair, but he has autism." These patterns of responses were also noted in the interview with Child 5 (older than child with a DD). In fact, she initially stated that all children in her home must follow rules, but the consequences for not following these rules were very different for each child: "Because my sister doesn't really get in trouble." She later justified her parents' behaviours by stating: "Because she has a problem, it's normal."

Distribution of responsibilities among the children. A wide range of responses were evoked when participants were asked:

In what ways has having a sibling with a disability meant extra responsibilities (e.g., caring for your sibling) for you? If so, are you okay/happy with the extra responsibilities or do you wish that you didn't have to do them? Why?

For instance, Child 7 (same age as child with a DD) stated:

Well, we do more stuff because I don't think he understands how to do everything, and for him it is long, so sometimes it's a little less fun because we have more chores to do, and he has fewer, so that's it.

She further stated:

I also have to clean my bedroom, and I have to help set up the table and clean it. But sometimes they let that go.... Sometimes I find, that's it, I find it a little unfair because he, he does less, but it depends sometimes. Sometimes I don't say anything, and sometimes it annoys me.

Likewise, Child 8 (same age as child with a DD) stated:

Yes, my room.... But my brother, like, my mother helps him a lot, and she helps me, too, but I really have to do it more on my own. I think it is normal, but it's still something that I don't find fair.

When prompted regarding whether she could think of other examples, Child 8 also mentioned:

If my mother asks me to do something, I do it, I linger around for a little bit, but I do it after; but my brother [with a DD], when he doesn't to do something, he walks away, and 
my parents never force him, and that I find a little unfair because I feel obligated, and he can just walk away and not do what was asked.

Several children also reported having greater responsibilities beyond typical household chores. Child 3 (younger than child with a DD) reported being responsible for her brother's medical and basic needs:

Well, when he has epileptic seizures, I absolutely need to go get the Diastat [medicine] and everything, and yes, sometimes I have to put him to bed because there are people over and my parents can't do it, but other than that I don't really have other responsibilities, usually it's like I do volunteer work.

Child 6 (younger than child with a DD) shared that she was responsible for making breakfast for her brother with a DD while on break from school:

During the summer, I am not happy; at some point I went to wake up my brother, my father and-I think it's last summer or the one before-it was like 9:15-9:30, "Okay, wake up and go make breakfast for my brother, for your brother after all." During the summer I make him breakfast, and it's really not cool, but I have no choice.

Child 5 (older than child with a DD) expressed being responsible for providing assistance to his sister with a DD on a daily basis:

Yes, like giving her milk, and looking after her and what she has-like, if her iPad is done and she cries, I have to go see her, restart her small show, or if her leg is not placed properly.

On the other hand, Child 9 (younger than child with a DD) did not report having extra responsibilities. Similarly, Child 10 (younger than child with a DD) mentioned that she and her brother (with a DD) have similar responsibilities.

Overall, children who are TD reported having many responsibilities, some of which may not be necessarily age appropriate.

\section{Parental Interviews Regarding Perceptions of Parental Differential Treatment and Fairness}

Although parents were interviewed separately, their experiences are presented collectively given the large overlap in their perceptions. The same three themes emerged across all parent interviews.

Time and attention dedicated to each child. Parents initially discussed how they divided up their time with each of their children. For example, Mother 9 shared that she spends a great amount of time with her child with a DD, especially with regard to homework completion: "Although we developed his [child with a DD] autonomy for homework, but he always needs support." Further, she mentioned:

He has to open his things, and he has to reread, so we have to develop these events. But, yes, he requires more time, but maybe not twice as much; he maybe requires one third more for me [compared to his sibling].

Although Father 2 attempted to behave in a similar fashion with both of his children, he expressed that he allocated more time to his child with a DD: 
Time yes. Attention not, not really. We, for sure.... Like I said earlier, we talk a lot to manage this, attention we don't want to give it, but because of his [child with a DD] status we do not have a choice.

Mother 3 had a different perspective on her family situation. She reported that her son with a DD required constant surveillance, which can be particularly time consuming. Perhaps in response to the lack of parental time and attention, her daughter who is TD pushes herself to perform at high academic levels in school:

He [child with a DD] is like a 2-3-year-old child. So, it's very intensive, it's constant, and extremely annoying.... I think that he, he is very grateful.... Extremely grateful. He knows that Mom loves him and knows that his dad loves him. And for him, it is very simple. It is very zen, and he lives in the present moment, and he does not worry about the relationships, I think he feels like it is solid.... She [child who is TD], it's like, "Oh, my god, if I don't perform well, my mom won't love me. Oh, my god, if I didn't do all my homework, or if my teacher warns me, nobody will love me anymore." She is extremely, very into performing and very, very into proving that she is a big girl and that she does what she has to do; and that I tell her all the time, we are not robots, everyone is human, everybody makes mistakes. When she makes a mistake, she becomes devastated: "Ahhhh I made a mistake!" She is very insecure in her relationship with us, and she is always thinking that it will crumble into pieces.

In sum, the lack of time appeared to be a significant issue for most parents in the present study and it clearly has an impact on the sibling(s) who are TD.

Parental perspectives on the demands and tasks imposed on their children. Parental expectations for children to carry household and other tasks was a common theme in the interviews. Most parents shared their perspective on how household chores and tasks were divided among their children. For instance, Mother 7 reported requesting more responsibilities from her children who are TD: "Sometimes they will tell me that I am unfair because I ask more from the girls [TD] than I ask from him [child with a DD] ... I would say that it revolves mostly around tasks." Father 7 revealed similar patterns and shared having different expectations for all his children. Specifically, the child with a DD was not expected to complete his household chores, which then required his siblings who are TD to complete the remaining tasks:

Well, what I just mentioned, inequality.... I can't ask the same thing to my son [child with a DD] that I ask the girls because they are TD.... He is different. Even if we tell the girls, they get frustrated and I understand, I would do the same.... He does tasks based on his abilities; the girls, we ask them to complete tasks, and all the time its, "Yeah, but he doesn't do it." Ya, but he is handicapped and not you. "Yes, but it's not fair."

Several parents also reported that their children who are TD were sometimes jealous due to this pattern of differential expectations and demands. For instance, Father 2 reported:

Well ... [child who is TD], we can't know with our other son [with a DD]. Well, he, I think he [child who is TD], I think it's okay, sometimes, on occasion, like a normal child he says, he will say, "That's it, you guys like him more than me." It's rare, he doesn't say it often but it's happened. Every time he says it, we take the time to sit down with him, and we took the time to explain to him, so I think it's okay. 
Similarly, Mother 4 discussed a situation she encountered:

I think that he [child who is TD] perceives that we give a lot to his sister (with a DD). At some point last year, he was saying, "You prefer her. It's her that you prefer, it's her, you want to get rid of me, you don't want me anymore."

Fathers 4 and 7 reported similar events, in which their child who is TD expressed his or her resentment and envy. For instance, Father 4 stated, "Well, I would say that he often blames us for spoiling his sister [with a DD], she is spoiled.... She receives a lot more gifts and everything." In the same vein, Father 7 mentioned "In one word, unequal.... I am certain that for the two girls [who are TD], they perceive, especially for one of the twins, it's illegal, unequal,... totally unequal."

Following from these reports, it is apparent that parents perceived that the child(ren) who are TD recognized parental differential treatment, which as discussed next, had an impact on family dynamics.

Parental views of family dynamics. The impact of the challenges involved with raising a child with a DD can sometimes be misunderstood by the siblings, which was a theme reported by many parents. For example, Mother 9 said, "Of course, oh yes, it makes her [child who is TD] bitter.... She feels rejected.... She feels rejected by her brother [with a DD]." Similarly, Mother 7 mentioned: "So grieving [for not having] a normal brother, this was the most difficult." Furthermore, Father 5 stated, "It maybe affects her [child who is TD] emotionally, she is a little ball of emotions."

Alternatively, Father 4 discussed a situation that his son who is TD encountered given the diagnosis of his sister, specifically, that he was a victim of intimidation at school:

Yes, I would tell you, we once celebrated a child's birthday here and his [child who is TD] friends said, "What is wrong with your sister [with a DD]?" ... It had even spread out, there were even repercussions at school... a little intimidation.... We had to work on this with him.

Lastly, Father 3 discussed the impact of daily challenges on his family:

Just the way we interact as a family because we're forced to, to co-operate... into, to how we deal with her [child who is TD]. So some stuff, you know, is, it's even little stuff like just getting ready, you know. He [with a DD] has trouble with motor skills...so getting him dressed, getting him out the door in the winter, is a big production; and at his age, you know, if he was normal, you know, you would say "Let's go," and he'd put his stuff on and close the door, we'd go. And you say that to her, and yet then you have to come along with him and get him all ready, get him going, and I think, you know, at times she feels a little bit... "I have to do everything on my own" and... You know? So, so yeah, it affects us in a way that - see, I don't know how to quite describe, it just puts added pressure on the family, you know, it puts pressure on her.

Overall, these statements represent some of the challenges (e.g., division of household chores, sibling's lack of understanding) that parents may encounter when raising a child with a DD. As noted below, the issue of fairness was raised by both children and parents. 


\section{Discussion}

\section{Children's Perceptions of Parental Differential Treatment and Family Life}

Differential control, affection, and fairness. Based on the questionnaire data, children perceived low levels of parental differential treatment with some indication that mothers provided slightly more differential control and affection to the sibling with a DD than fathers did. The mean differences between children's ratings of maternal and paternal affection were very close, while those for control appeared to show somewhat larger differences. In addition, children rated parents' behaviour as generally fair. Overall, the pattern of these findings is in line with literature examining parental differential treatment in families with and without a child with a disability (Kowal \& Kramer, 1997; McHale \& Pawletko, 1992; Quittner \& Opipari, 1994). Interestingly, the interviews provide a more nuanced view of parental differential treatment and family life.

Family life with a sibling with a DD. The interviews afforded children the opportunity to reflect on their experiences with their parents and the consequences associated with having a sibling with a DD. A number of themes were apparent in children's discussion of family life; specifically, children reported a variety of experiences with respect to completing activities with their parents. Some ventured to weekly events and outings, whereas others spent quality time with their parents exclusively when their sibling with a DD was in respite care. Other children reported spending time with their mothers and fathers sporadically or not at all. These findings may be worrisome given that some children who are TD may not be receiving adequate daily attention, which may possibly have negative social-emotional or behavioral outcomes (Goudie, Havercamp, Jamieson, \& Sahr, 2013). This was also an issue that parents identified as problematic in some cases, suggesting that perhaps some forms of intervention may be required. It is important to acknowledge that the findings regarding levels of attention may not necessarily be a phenomenon solely observed in families of children with a DD.

Most children reported having rules that differed in magnitude and fairness in comparison to their sibling with a DD. Frequently, parents offered alternative consequences that required less response effort for the child with a DD. Rule implementation was often perceived as unfair by the children who are TD, which they justified due to the sibling's DD. These findings further endorse the argument that children may rationalize unequal treatment and recognize that it seems unfair and they may not like it, because their siblings have needs that necessitate greater parental care (Kowal \& Kramer, 1997; Meunier et al., 2012). Some children appeared to recognize the reality of the situation and accept it, given that they have no choice in the matter.

In nearly all households, the children who are TD were responsible for completing additional tasks, sometimes independently, and occasionally, ones that were not necessarily suitable for their age. As a result, a handful of participants reported feeling frustrated and annoyed; some children justified their parents' behaviour by stating that these additional responsibilities were due to their sibling's lack of understanding and inability to complete the task. Thus, children were able to demonstrate an understanding for the unequal distribution of responsibilities. Similarly, McHale and Pawletko (1992) 
reported that some participants described feeling apprehensive and rejected, despite recognizing that their siblings' needs necessitated more time and attention. Future research might attempt to determine whether the gender of the child who is TD is related to the present findings regarding responsibility.

In conclusion, distributive justice theory highlights the need to take children's viewpoints on parental differential treatment into account, especially with respect to whether they consider it necessary and fair (Deutsch, 1985; McHale \& Pawletko, 1992; Sabbagh \& Schmitt, 2016). Children appear to have an understanding that parental resource allocation may not always be equal (Deutsch, 1985); they mentioned that the dissimilarity in treatment was unfair and sometimes, they attempted to rationalize their parents' behaviours. How this pattern might evolve over time and its impact on the quality of parent-child and also sibling relationships is a question for future research.

\section{Parents' Perceptions of Differential Treatment and Family Life}

Differential control, affection, and fairness. On the questionnaires, parents reported that they engaged in relatively equal levels of differential affection and control with both children. The means for both sub-scales were very similar for mothers and fathers, suggesting perhaps that parents perceived that they treated their children relatively equally. An analysis of the parents' perceptions during the interviews provided richer information and allowed parents an opportunity to express their views in more detail. Given that mothers' and fathers' responses during the interviews were very similar, we opted to combine their perceptions rather than reporting them separately.

Family life with a child with a DD. Several factors may influence a home environment, that is, how a family functions as a whole (Dunn, 1992). Schuntermann (2007) argued that having a child with a DD may indicate that a family faces unusual challenges (e.g., behavioural issues, greater need for attention and care). It is commonly reported that children with a DD require more assistance than those without a diagnosis (e.g., Minihan, Must, Anderson, Popper, \& Dworetzky, 2011) as was also revealed in our findings. As Jensen et al. (2013) discussed, most parents attempt to allocate similar amounts of time and energy to each child; yet, it is often difficult for them to do so given the needs of the child with a DD (Horn \& Kang, 2012). This inequality of parental time and energy leaves fewer occasions to develop relationships with their other children, as reflected in both the child and parent interviews. Jensen et al. (2013) found associations between favouritism from both parents and children's well-being. We did not assess child well-being directly, but a review of some of the children's interview responses suggests that this is an important question for future research (McHale, Updegraff, JacksonNewsom, Tucker, \& Crouter, 2000).

Generally, parents required their children to complete household chores, as well as other tasks around their home. These expectations were adjusted for the child with a DD. When asked to discuss demands and tasks allocated to each child, most mothers and fathers agreed that they expected their child(ren) who is (are) TD to be responsible for completing a greater amount of work than their sibling with a DD. Overall, parental expectations notably differed for children; and parents recognized it sometimes generated feelings of jealousy, resentment, and envy in their children who are TD. These findings 
are in agreement with those of Russell (2003), who argued that parental expectations are based on children's development and needs. Nevertheless, parents must deal with the emotional responses of their children who are asked to assume a greater share of household tasks. It was concerning that some parents were asking their children to assume quite a large degree of responsibility for the child with a DD regarding medical or nutritional needs. Perhaps this reflects that parents had limited resources or outside sources of support, and thus had to rely on the child who is TD to provide assistance that, in some cases, perhaps may not be developmentally appropriate.

Lastly, consistent with Dunn (1992), several mothers and fathers concurred that their children who are TD were impacted to different extents by the DD of their sibling. For instance, a few parents reported that their children did not understand the nature of their sibling's DD, which resulted in bitterness and feelings of rejection. Further, one parent mentioned that their child who is TD became a victim of intimidation following an event that the sibling with a DD attended. These experiences clearly indicate that the families were undergoing stressful experiences and perhaps might have benefitted from outside support and resources. In conclusion, it was apparent that family life while at times positive, can also be a struggle for these families in terms of balancing the needs of all children and providing the appropriate level of care and attention in equitable ways.

\section{Conclusions}

Some limitations of the current study should be noted. First, the logistics surrounding recruitment may have prevented us from accessing certain populations. Although flyers were distributed using social media (e.g., Facebook), not all families use social networking websites. Second, since only a small sample was recruited, the participants' experiences may not reflect those of the greater population. Third, the lack of detailed information on the degree of functioning of the siblings with a DD should be noted; this prevented investigating how the findings might differ based on the needs of the siblings. Lastly, it should be noted that the siblings had a variety of diagnoses, thus we were not able to determine whether the specific diagnosis had a direct influence on the findings. Nevertheless, the interviews provided rich data for an analysis of family perceptions of the dynamics associated with having a child with a DD.

The present study provided insight into these families' daily lives, as well as the unique challenges that may not be present in families in which all the children are TD. Specifically, it was reported that children who are TD have additional tasks and different rules in comparison to their siblings with a DD. Additionally, it appeared that most children with a DD required more help and support from parents, which, in turn, left little time for siblings who are TD. Interestingly, both children and parents were cognizant of differential treatment and expectations for the children with and without a DD and provided a clear understanding and justification for these behaviors. Although children's questionnaire ratings regarding differential parental treatment indicated that they rated it as fair, the interview responses suggested that while they could accept the differential treatment, it did not come without some consequences. Our study provides a number of original contributions to the literature on functioning in families with a child with a DD. It also raises a number of avenues for future research concerning the role of different 
family structures (e.g., single parent, lesbian, gay, bisexual, and transgender parents), gendered responsibilities, the severity of the child's diagnosis, and level of functioning on family dynamics.

Our findings may inform government agencies and professionals of changes that might benefit the current social services and educational systems and practices. Further, our data highlighted the need for respite programs, services tailored to families with children with a DD, as well as specialized interventions. From these considerations, future research should consider addressing the abovementioned limitations, as well as extending the current study by conducting systematic observations of families in their daily lives.

\section{References}

Bizier, C., Fawcett, G., Gilbert, S., \& Marshall, C. (2012). Developmental disabilities among Canadian ages 15 years and older, 2012 (Report). Ottawa, ON: Statistics Canada. Retrieved from https://www150.statcan.gc.ca/n1/pub/89-654-x/89-654-x2015003-eng.htm

Brody, G. H., Stoneman, Z., \& McCoy, J. K. (1992). Associations of maternal and paternal direct and differential behavior with sibling relationships: Contemporaneous and longitudinal analyses. Child Development, 63, 82-92. doi:10.1111/j.1467-8624.1992.tb03597.x

Daniels, D., \& Plomin, R. (1985). Differential experience of siblings in the same family. Developmental Psychology, 21, 747-760. doi:10.1037/0012-1649.21.5.747

Dette-Hagenmeyer, D., \& Reichle, B. (2016). Justice in the couple and the family. In C. Sabbagh \& M. Schmitt (Eds.), Handbook of social justice theory and research (pp. 333-347). New York, NY: Springer.

Deutsch, M. (1985). Distributive justice: A social-psychological perspective. New Haven, CT: Yale University Press.

Dunn. J. (1992). Sisters and brothers: Current issues in developmental research. In F. Boer \& J. Dunn (Eds.), Children's sibling relationships: Developmental and clinical issues (pp. 1-17). Hillsdale, NJ: Erlbaum.

Dyson, L. L. (1989). Adjustment of siblings of handicapped children: A comparison. Journal of Pediatric Psychiatry, 14, 215-219. doi:10.1093/jpepsy/14.2.215

Engle, P. L., \& Black, M. M. (2008). The effect of poverty on child development and educational outcomes. Annals of the New York Academy of Sciences, 1136, 243-256. doi:10.1196/annals.1425.023

Goldberg, S., Marcovitch, S., McGregor, D., \& Lojkasek, M. (1986). Family responses to developmentally delayed preschoolers: Etiology and the father's role. American Journal of Mental Deficiency, 90, 610-617.

Goudie, A., Havercamp, S., Jamieson, B., \& Sahr, T. (2013). Assessing functional impairment in siblings living with children with disabilities. Pediatrics, 132, e476-e483.

Hays, D. G., \& Singh, A. A. (2012). Qualitative inquiry in clinical and educational settings. New York, NY: Guilford.

Hodgetts, S., Zwaigenbaum, L., \& Nicholas, D. (2015). Profile and predictors of service needs for families of children with autism spectrum disorders. Autism, 19, 673-683. doi: $10.1177 / 1362361314543531$ 
Hoefman, R., Payakachat, N., Van Exel, J., Kuhlthau, K., Kovacs, E., Pyne, J., \& Tilford, J. M. (2014). Caring for a child with autism spectrum disorder and parent's quality of life: Application of the CarerQol. Journal of Autism and Developmental Disorders, 44, 19331945. doi:10.1007/s10803-014-2066-1

Horn, E. M., \& Kang, J. (2012). Supporting young children with multiple disabilities: What do we know and what do we still need to learn? Topics in Early Children Special Education, 31, 241-248. doi:10.1177/0271121411426487

Jensen, A. C., Whiteman, S. D., Fingerman, K. L., \& Birditt, K. S. (2013). Life still isn't fair: Parental differential treatment of young adult siblings. Journal of Marriage and Family, 75, 438-452. doi:10.1111/jomf.12002

Kowal, A., \& Kramer, L. (1997). Children's understanding of parental differential treatment. Child Development, 68, 113-126. doi:10.2307/1131929

Kowal, A., Kramer, L., Krull, J. L., \& Crick, N. R. (2002). Children's perceptions of the fairness of parental preferential treatment and their socioemotional well-being. Journal of Family Psychology, 16, 297-306. doi:10.1037/0893-3200.16.3.297

McHale, S. M., \& Pawletko, T. M. (1992). Differential treatment of siblings in two family contexts. Child Development, 63, 68-81. doi:10.2307/1130902

McHale, S. M., Crouter, A. C., McGuire, S. A., \& Updegraff, K. A. (1995). Congruence between mothers' and fathers' differential treatment of siblings: Links with family relations and children's well-being. Child Development, 66, 116-128. doi:10.2307/1131194

McHale, S. M., Updegraff, K. A., Jackson-Newsom, J., Tucker, C. J., \& Crouter, A. C. (2000). When does parents' differential treatment have negative implications for siblings? Social Development, 9, 149-172. doi:10.1111/1467-9507.00117

Mereoiu, M., Bland, C., Dobbins, N., \& Niemeyer, J. A. (2015). Exploring perspectives on child care with families of children with autism. Early Childhood Research and Practice, 17(1), 1-13.

Meunier, J. C., Roskam, I., Stievenart, M., Van, D. M. G., Browne, D. T., \& Wade, M. (2012). Parental differential treatment, child's externalizing behavior and sibling relationships: Bridging links with children's perception of favoritism and personality, and parents' self-efficacy. Journal of Social and Personal Relationships, 29, 612-638. doi:10.1177/0265407512443419

Minihan, P. M., Must, A., Anderson, B., Popper, B., \& Dworetzky, B. (2011). Children with special health care needs: Acknowledging the dilemma of difference in policy responses to obesity. Preventing Chronic Disease, 8, 95.

Quittner, A. L., \& Opipari, L. C. (1994). Differential treatment of siblings: Interview and diary analyses comparing two family contexts. Child Development, 65, 800-814. doi:10.1111/j.1467-8624.1994.tb00784.x

Russell, F. (2003). The expectations of parents of disabled children. British Journal of Special Education, 30, 144-149. doi:10.1111/1467-8527.00300

Sabbagh, C., \& Schmitt, M. (2016). Handbook of social justice theory and research. New York, NY: Springer.

Saldaña, J. (2013). The coding manual for qualitative researchers. Thousand Oaks, CA: Sage.

Schuntermann, P. (2007). The sibling experience: Growing up with a child who has pervasive developmental disorder or mental retardation. Harvard Review of Psychiatry, 15(3), 93-108. doi:10.1080/10673220701432188

Statistics Canada. (2018). Surveillance of autism spectrum disorder (ASD) [Web page]. Retrieved from https://www.canada.ca/en/public-health/services/diseases/autism-spectrum-disorder-asd /surveillance-autism-spectrum-disorder-asd.html 
Volling, B. L., \& Belsky, J. (1992). The contribution of mother-child and father-child relationships to the quality of sibling interaction: A longitudinal study. Child Development, 63, 1209-1222. doi: $10.2307 / 1131528$

Weiss, J. A., Wingsiong, A., \& Lunsky, Y. (2014). Defining crisis in families of individuals with autism spectrum disorders. Autism, 18, 985-995. doi:10.1177/1362361313508024

Wolf, L., Fisman, S., Ellison, D., \& Freeman, T. (1998). Effect of sibling perception of differential parental treatment in sibling dyads with one disabled child. Journal of the American Academy of Child and Adolescent Psychiatry, 37, 1317-1325. doi:10.1097/00004583-199812000-00016

\section{Authors' Note}

This study was supported by a Social Sciences and Humanities Research Council of Canada strategic research grant and the Concordia University Research Chair in Early Childhood Development and Education to the second author. We thank the children and families who participated in this study, as well as Catherine Bergeron, Kim Koch, and Ryan Persram for research assistance.

Please address correspondence to Nina Howe, Dept. of Education, Concordia University, 1455 de Maisonneuve West, Montreal, QC, H3G 1M8, Canada. Email: nina.howe@concordia.ca 